\title{
PRODUÇÃO TEXTUAL E LEITURA NO CONTEXTO ESCOLAR
}

\author{
ELIANE FIORESE ${ }^{1}$ \\ elianefiorese@uol.com.br
}

\begin{abstract}
Education must happen with responsibility, because it requires from educator a constant dedication and improvement. We know the school environment may propitiate the development of efficient practices, which aims interaction of the person with the society, which it lives. In this article they settled down considerations on the reading and production text, aiming to establish the importance to these relations and to address a new one to look front to the educational process for the current day.
\end{abstract}

KEYWORDS: Theory. Practice. Teaching. Education

\section{INTRODUÇÃO}

Todo o profissional de Letras se preocupa com o quanto e o que seus alunos lêem, pois ler não é somente coletar informações, como no caso de uma leitura técnica ou informativa, mas também ter a possibilidade de soltar as rédeas da imaginação e da criatividade no caso de diferentes formas de leitura e textualidade.

Sendo a leitura um procedimento básico, indispensável à aprendizagem e conseqüentemente indispensável para boa produção textual, considera-se de fundamental importância estimular a prática de leitura em sala de aula e a produção de textos. Se os alunos adquirirem algumas técnicas importantes e escreverem com regularidade, aumentarão as possibilidades de produção de textos coesos, claros e coerentes.

No referido artigo tenciona-se, além de relevar o ensino da leitura e a prática de produção textual, incentivar a criatividade, diversificando assim atividades ensino e aprendizagem em sala de aula, ou seja, a pesquisa parte dos fundamentos teóricos para tais práticas. Primeiramente, apresentar-se-á alguns aspectos teóricos que abordará o ensino de leitura e a prática textual na perspectiva de

1 Aluna do Programa de Pós-Graduação em Lingüística: Ensino da Língua e Literatura da UNICRUZ - UNIVERSIDADE DE CRUZ ALTA, sob orientação do professor Doutor Marcos Gustavo Richter. 
Bamberger, Rangel, Platão e Fiorin, Richter. Na seqüência, uma breve reflexão com foco no confronto Teoria e Prática, seguido das considerações finais.

\title{
O ENSINO DE LEITURA E SUA IMPORTÂNCIA
}

Inicialmeste, este estudo direciona para um novo conceito de leitura para os dias atuais. Não basta completar a escolaridade exigida, pois os avanços tecnológicos exigem uma educação permanente, na qual 0 indivíduo se atualize constantemente a fim de se integrar no contexto global.

Nas atividades de ensino - aprendizagem, a leitura é indispensável, pois ela pode vir ao encontro dos interesses e necessidades além de desenvolver a capacidade crítica do educando. Esses aspectos só serão acessíveis a quem tiver o domínio das técnicas da leitura.

Bamberger (1987) aponta quatro importantes objetivos do ensino da leitura para aprimorar o conhecimento tais como: a auto-realização, diversão, ampliação constante dos interesses da leitura e interesse permanente. Indica também inúmeras técnicas e estratégias especiais para promover uma leitura eficaz, bem como a leitura silenciosa. Isto pode contribuir para uma melhor compreensão do texto.

De acordo com a Rangel (2001, p.9)

\begin{abstract}
$\mathrm{O}$ ato de ler admite, hoje, várias considerações. Nada, equipamento algum, substitui a leitura. Mesmo numa época em que proliferam os recursos audiovisuais e as "máquinas" ou "mecanismos" de ensinar, mesmo numa época em que a informática se impõe com todo o seu poder econômico e processual, pode-se re-afirmar: Nada, equipamento algum, substitui a leitura. Ler é uma prática básica, essencial, para aprender.
\end{abstract}

Para autora, quanto mais o hábito da leitura é desenvolvido, mais experiência o aluno adquire, desenvolvendo seu potencial e melhorando seu desempenho como leitor. Leitura é prática. Só dessa forma desenvolve-se o conhecimento sobre o léxico, ou seja, amplia-se o vocabulário de palavras desconhecidas. Além do léxico, desenvolve-se também outros domínios lingüísticos, como diferentes formas de construção sintática, isto é, formas de combinar palavras ou de construções de frases.

Existem três modelos básicos de leitura:

1. Modelo de Gough - ascendente (bottom-up: das partes para o todo); o leitor constrói o texto das pequenas unidades. Parte das letras para palavras para frases para sentenças, ou seja, constrói o significado com base nos dados do texto. Faz pouca leitura nas entrelinhas do texto, detendo-se mais nas palavras, dando atenção às partes menores do texto.

2. Modelo de Goodman - descendente (top-down: do todo para as partes); os leitores trazem o seu próprio conhecimento. Este tipo de leitura privilegia o leitor que aprende rapidamente as idéias gerais e essenciais do texto, 
é fluente, mas deve ter cuidado para não fazer excessos de adivinhações do significado geral.

3. Modelo de Rumelhart - interativo ( bottom-up e top- down simultânea ou paralelamente); ambos os tipos de estratégias acima entram em jogo de forma balanceada, de acordo com os objetivos do leitor e os problemas de leitura que enfrenta. $O$ ensino de leitura que considera tanto estratégias top-down quanto bottom-up prepara plenamente o aprendiz para esta macro-habilidade.

O professor deve, também, levar em consideração as preferências de seus alunos, pois existe um grande conflito em ler por interesse e ler por obrigação. Logo, o aluno jamais vai ler aquilo que não é de seu interesse, o que o incentivará a desistir do hábito de ler e conseqüentemente terá dificuldades na produção textual.

\section{PRODUÇÃO TEXTUAL}

Redigir exige requisitos próprios, tais como, saber ler e saber entender. Qualquer redator deve motivar-se a partir da leitura de bons textos para, com base no que leu criar um novo texto. Faulstich (2004) afirma que produzir textos não é uma tarefa fácil, tanto para quem pretende ensiná-la como para aquele que, na sala de aula, todos os dias, dispõe-se a aprendê-la.

Escrever é transmitir para as pessoas alegrias, tristezas, medos, desejos, anseios, e posições diante dos fatos. Significa passar conhecimentos, informações e, sobretudo, o legado cultural da humanidade. Uma idéia constantemente difundida, porém errônea, é a de que apenas alguns poucos podem escrever bem. Entretanto a escrita de qualidade exige treino e dedicação. Os jornalistas e os escritores só conseguiram produzir textos com clareza, correção e que despertassem o interesse do leitor após sucessivas tentativas, erros e acertos.

As dificuldades na expressão de idéias, em alguns casos surgem porque elas não estão amadurecidas ou não possuem informações suficientes para desenvolvêlas. Elas podem ser sanadas pela leitura de obras literárias, de jornais e revistas. Além disso, assistir a bons filmes, peças de teatro, ouvir músicas de qualidade, visitar museus e exposições faz com que aumente o repertório cultural e os conhecimentos.

A oralidade e a escrita são complementares e não se pode considerar a aprendizagem da leitura e da produção textual como transição do mundo da voz para o mundo da letra, mas como uma inter-relação entre esses dois mundos. A explicitação dos mecanismos de produção de sentido do texto contribui decisivamente para melhorar o desempenho do aluno na leitura e na escrita.

De acordo com Platão e Fiorin (2003), os conhecimentos necessários para ler e produzir textos são de três níveis: conhecimento do contexto sócio-histórico em 
que o texto foi construído, conhecimento do sistema lingüístico, conhecimento dos mecanismos de estruturação do significado. Os autores explicam como um texto se relaciona com outros textos e explicitam os variados processos de construção do significado (estruturas narrativas, temas, expediente de coesão e de argumentação, recursos expressivos...). Segundo eles, o texto se organiza em três níveis distintos de estruturação:

- Nível mais superficial: estrutura discursiva;

- Nível intermediário: estrutura narrativa;

- Nível mais profundo: estrutura profunda

Martins e Zilberknop (2001) afirmam que um texto, em geral, apresenta características mistas, torna-se muito complexa a delimitação de seus traços específicos. Dessa forma, o importante, na redação textual, é que haja uma idéia em torno da qual se possa considerar um núcleo, os dados que apóiam essa afirmação e a relação entre ambos.

Para tanto, a maneira mais simples (de vencer o tormento) de fazer uma redação, e de que todos dispõem, é falando sobre ela mesma, sobre o tema dado, o assunto pedido. Não há que se inventar nada. Ele já está lá, à disposição. Dessa forma, não há porque temê-lo, mas apreciá-lo pelas vantagens que podem ser oferecidas.

Sabe-se que a leitura e a produção de textos exigem estímulo e compete ao educador fazer uso de material variado e rico em leitura. Por outro lado, Rangel (2001) afirma que não basta apenas recomendar ao aluno que leia o texto muitas vezes, é preciso mostrar-lhe para onde dirigir a atenção, uma vez que a leitura liberta, aprimora a linguagem, a expressão individual e coletiva.

\section{TEORIA X PRÁTICA}

Para muitos, elaborar textos, é uma tarefa difícil determinando assim o seu insucesso. Para que isso não ocorra é necessário que o educador de algumas sugestões para "Inícios", sobre como "Desenvolver" e "Concluir" um assunto.

Faulstich (2004) afirma que se o aluno aprender bem as capacidades cognitivas (compreensão, análise, síntese, avaliação, aplicação) ele ficará apto a entenderinterpretar textos e a redigir com maior segurança. Trabalhando de forma incentivadora, sentirão menos dificuldades em produzir textos e de forma mais criativa desenvolverão as suas histórias.

Vale salientar que se for levado em consideração as preferências dos envolvidos, será possível realizar uma atividade diferenciada e criativa, do interesse do aluno, assim como as atividades realizadas em duplas, que criarão situações para o exercício da linguagem oral e escrita, gerando um movimento entre pensamento e linguagem. 
A linguagem interativa, segundo Richter (2000), é mais rica não só quantitativa, mas também qualitativamente, se comparada com aquela produzida pelos alunos em ambientes nos quais o professor comanda o direito de perguntar, escolher quem fala e o que fala. $O$ trabalho em pequenos grupos ajuda os alunos a se tornarem mais participativos, mais responsáveis e mais autônomos.

Para Lima (2004), trabalhar com os aluno em duplas favorece o desenvolvimento social e intelectual deles, pois, ao realizar uma atividade em duplas ou em grupo, eles terão oportunidade de trocar idéias, socializar-se, escutar a opinião do outro, superar as dificuldades, tornando o processo fácil e dinâmico.

O educador também pode, ao formar duplas, selecionar seus componentes de acordo com as dificuldades de aprendizagem, organizando grupos heterogêneos, nos quais os alunos com bom desenvolvimento pedagógico se unam com os alunos com dificuldades, tornando o processo fácil e dinâmico

Sabe-se que a leitura e a escrita se inter-relacionam e que o aluno desenvolverá a linguagem escrita para as produções sendo um leitor ativo. Para isso, é muito importante o ambiente familiar na formação do hábito da leitura, mas as maiores expectativas convergem ao professor. É ele quem vai indicar os livros ao aluno, oferecendo-Ihe um repertório de títulos em que possam se movimentar, segundo suas preferências e interesses.

Um dos primeiros passos para a formação do hábito da leitura na escola, segundo Aguiar (1993) diz respeito à seleção do material, e que alguns critérios devem ser levados em conta, como a finalidade da leitura e a qualidade do material.

A leitura é procedimento básico, indispensável à aprendizagem e conseqüentemente fundamental para que o educando desenvolva produções textuais. Entretanto, o interesse do aluno em leituras tem sido precário. Tendo isto em vista é necessário que o educador apresente dinâmicas de leitura para a sala de aula. É por isso que Rangel (2001, p.15) afirma:

As dinâmicas de leitura são utilizadas para auxiliar e para fixar a aprendizagem, para introduzir elementos que estimulem o trabalho de ler e aprender, para incentivar habilidades necessárias ao estudo ( observação, organização e expressão de idéias etc.), para diversificar em todos os graus de ensino e em qualquer disciplina.

Precisa-se fazer da sala de aula um espaço em que as atividades desafiem constantemente o aluno a pensar, conhecer, informar-se e criticar, construindo o seu conhecimento. É através da leitura e da escrita que se forma o cidadão, com uma personalidade mais crítica e libertadora.

Através da leitura, adquire-se experiências que além de facilitarem o aprendizado, são também fontes de estímulo que impulsionam a descoberta, elaboração e difusão do conhecimento. Para Silva (1997) saber ler e executar esse ato é possuir mais elementos para pensar a realidade e sobre as condições de vida. É 
uma habilidade humana que permite o acesso do povo aos bens culturais já produzidos e registrados pela escrita

\section{CONSIDERAÇÕES FINAIS}

A produção textual, hoje, é uma das exigências de um bom ensino de línguas. Portanto, somos "induzidos" a falar bem e conseqüentemente a escrever bem, mas acredita-se que isso só será possível com boas práticas no ensino da leitura. Ela nos permite compreender e interpretar a realidade por meio da escrita.

Assim como falar se aprende falando, pode-se dizer que ler e escrever se aprende da mesma forma: praticando. A leitura é uma ferramenta essencial do conhecimento, pois mesmo a possibilidade de se escrever bons textos tem origem na leitura. Quanto mais os alunos lerem, e lerem criticamente, mais fácil será de desenvolver a habilidade da escrita.

É válido afirmar que é recomendável empregar não apenas uma técnica didática, mas uma gama de opções, cuja eficácia também deve ser avaliada por investigação em sala de aula, ou seja, pesquisa-ação.

A oralidade e a escrita são complementares e não se pode considerar a aprendizagem da leitura e da produção textual como transição do mundo da voz para o mundo da letra, mas como uma inter-relação entre esses dois mundos. Mesmo que a realidade dos educandos está distante da realidade ideal, julga-se não ser impossível, uma vez que a leitura desacomoda e abre perspectivas infinitas.

\section{REFERÊNCIAS BIBLIOGRÁFICAS}

BAMBERGER, Richard. Como Incentivar o Hábito da Leitura. São Paulo: Cultrix, 1987

FAULSTICH, Emile L. de J. Como Ler, Entender e Redigir um Texto. Petrópolis: Editora Vozes, 2004

JOLIBERT, Josette. Formando Crianças Produtoras de Textos. Porto Alegre: ARTMED, 1994

AGUIAR, Vera Teixeira de \& BORDINI, Maria da Glória. A formação do leitor: alternativas metodológicas. Mercado Aberto. Porto Alegre, 1993.

LIMA, Regina Vilhaça. Oficina de Textos. Belo Horizonte, MG, 2004.

MARTINS, Dileta Silveira e ZILBERKNOP, Lúbia Scliar. Português Instrumental: Porto Alegre: Sagra Luzzatto, 2001

PLATÃO\&FIORIN. Para Entender o Texto: Leitura e Redação. São Paulo: Editora Ática, 2003

RANGEL, Mary. Dinâmicas de Leitura para Sala de Aula. Petrópolis: Editora Vozes, 2001

RICHTER, Marcos Gustavo. Ensino do Português e Interatividade.Santa Maria: Editora ufsm,2000 


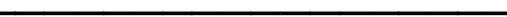

